\title{
Efektivitas Pelayanan Izin Mendirikan Bangunan Di Kabupaten Lebak
}

\author{
Ailia Lailatul Qodariah'1, Delly Maulana², Rachmi Yulianti ${ }^{3}$ \\ ${ }^{1}$ Mahasiswa Administrasi Publik, Fakultas Ilmu Sosial, Ilmu Politik, dan Ilmu Hukum \\ Universitas Serang Raya, Jl .Serang Cilegon KM 5 Serang, Banten, Indonesia \\ ${ }^{23}$ Program Studi Administrasi Publik, Fakultas Ilmu Sosial, Ilmu Politik, dan Ilmu Hukum \\ Universitas Serang Raya, Jl .Serang Cilegon KM 5 Serang, Banten, Indonesia
}

\begin{abstract}
This article discusses about effectiveness of service on DPMPTSP of the Lebak district as well as barriers and solutions in implementing services. In practice, public considers the procedure of IMB's licensing are hard to understand and complicated so that public and business actors have not processed building permits. The method used in this research is descriptive qualitative method, this research uses data collection methods in the form of observation, interviews and documentation. The result showed that the performance of DPMPTSP's employees are quite good. This can be seen from the increase in the number of people applying for IMB's licensing because public trust in the government, especially on DPMPTSP of the Lebak district who has served them well. However, there are some people and business actors who also have minimal information regarding IMB's licensing so that this becomes tasks for local governments to increase development and local revenue through permissions available on DPMPTSP of the Lebak district.
\end{abstract}

Keywords: Development, Licensing, Service

\begin{abstract}
Abstrak
Artikel ini membahas tentang keefektifan pelayanan pada DPMPTSP Kabupaten Lebak serta hambatan dan solusinya dalam melaksanakan pelayanan. Dalam pelaksanaanya, masyarakat menganggap prosedur perizinan Izin Mendirikan Bangunan (IMB) sulit dipahami dan berbelit-belit sehingga banyak masyarakat maupun pelaku usaha belum mengurus perizinan bangunannya. Metode yang digunakan dalam penelitian ini adalah metode kualitatif deskriptif, penelitian ini menggunakan metode pengumpulan data berupa observasi, wawancara dan dokumentasi. Hasil penelitian menunjukan bahwa kinerja pegawai Dinas Penanaman Modal dan Pelayanan Terpadu Satu Pintu dikatakan sudah cukup baik. Hal ini dapat dilihat dari meningkatnya masyarakat yang mengajukan dokumen perizinan Izin Mendirikan Bangunan (IMB) karena kepercayaan masyarakat terhadap pemerintah khususnya pada DPMPTSP Kabupaten Lebak yang telah melayani mereka dengan baik. Namun, masih ada sebagian masyarat serta pelaku usaha juga memiliki informasi yang minim terkait perizinan Izin Mendirikan Bangunan (IMB) sehingga ini menjadi PR bagi pemerintah daerah untuk meningkatkan pembangunan dan Pendapatan Asli Daerah (PAD) melalui perizinan yang tersedia pada DPMPTSP Kabupaten Lebak.
\end{abstract}

Kata Kunci : Pembangunan, Perizinan, Pelayanan

*)Penulis Korespondensi

E-mail : ailialq2112@gmail.com 


\section{PENDAHULUAN}

Pelayanan publik adalah pelayanan yang diberikan oleh organisasi/badan pemberi layanan untuk melayani kepentingan masyarakat sesuai peraturan yang telah ditetapkan oleh masing-masing instansi penyedia layanan. Penyelenggaraan pelayanan publik harus memperhatikan pelaksanaan penyelenggaraan, tingkat kepuasan masyarakat, biaya, penyelesaian terkait produk yang dibuat, serta evaluasi kinerja pegawai pada organisasi yang menyediakan pelayanan.

Katz dan Kahn yang dikutip Richard M Steers (1985:54) mendefinisikan efektivitas sebagai suatu usaha untuk mencapai keuntungan maksimal bagi organisasi dengan segala cara. (Steers, 1985).

Pelayanan akan dapat dikatakan efektif apabila masyarakat mendapatkan pelayanan yang mereka harapkan seperti pelayanan yang memiliki prosedur singkat, tepat, cepat, dan hasilnya memuaskan. Akan tetapi, yang dapat menentukan faktor dari keberhasilan efektivitas tersebut adalah kinerja serta kedisiplinan aparat pelayanan.

Tingkat efektivitas pelayanan dapat diukur dengan cara membandingkan rencana atau tujuan yang telah ditentukan dengan hasil yang telah dicapai, maka usaha atau hasil pekerjaan tersebut itulah dapat dikatakan efektif, akan tetapi apabila usaha atau hasil pekerjaan yang telah dilakukan tidak tercapai sesuai dengan apa yang direncanakan, maka hal tersebut dapat dikatakan tidak efektif. (Candra et al., 2018)

Penyelenggaraan perizinan terbentuk dari suatu proses dalam rangka mencari pola yang terbaik dalam memberikan pelayanan perizinan kepada masyarakat. Pelayanan yang diberikan kepada masyarakat dalam penyelenggaraan perizinan dapat dilaksanakan dengan mekanisme yang telah ditetapkan serta terdapat alur dan prosedur dalam pelayanan publik. Tujuan dan sasaran dalam penyelenggaraan pelayanan perizinan yaitu agar dapat mewujudkan pelayanan publik yang cepat, tepat, murah, mudah, transparan, pasti dan terjangkau, serta mampu meningkatkan hak-hak masyarakat dalam pelayanan publik. (Ningsih \& Hardianto, 2019)

Salah satu contoh dari pelayanan perizinan yaitu Izin Mendirikan Bangunan yang termasuk bagian dari pelayanan publik. Izin mendirikan bangunan (IMB) adalah perizinan dalam rangka kegiatan pembangunan bangunan baru, mengubah bangunan, memperluas atau mengurangi bangunan serta merawat bangunan sesuai dengan persyaratan teknis dan administratif yang berlaku yang nantinya akan diberikan oleh kepala daerah kepada pemilik bangunan.

Instansi yang bertugas melayani pelayanan perizinan terkait Izin Mendirikan Bangunan (IMB) ini adalah Dinas Penanaman Modal dan Pelayanan Terpadu Satu Pintu (DPMPTSP). DPMPTSP memiliki tugas umum melaksanakan kegiatan urusan pemerintahan serta pembangunan di bidang penanaman modal dan penyelenggaraan perizinan dan non-perizinan secara sistematis. Sebelum mendirikan bangunan/mengubah bangunan, masyarakat harus memiliki izin tentang kelayakan, kenyamanan, keamanan untuk bangunan nantinya serta kepastian hukum terlebih 
dahulu sesuai dengan persyaratan yang telah tertera dalam Izin Mendirikan Bangunan. Akan tetapi pada pelaksanaannya, tidak semua sesuatu yang terjadi di lapangan dapat berjalan dengan baik karena dalam hal ini berbagai permasalahan juga kerap kali dapat terjadi seperti masih ada masyarakat yang belum memahami bahwa pajak atau iuran dari Izin Mendirikan Bangunan (IMB) yang telah mereka bayarkan dapat berkontribusi bagi pembangunan daerah. (Irfansyah, 2015). Selain itu, Banyak masyarakat yang masih mengeluhkan pelayanan pembuatan perizinan IMB (Izin Mendirikan Bangunan) tersebut dikarenakan persyaratannya yang rumit.

Lahirnya Peraturan Daerah Kabupaten Lebak Nomor 9 Tahun 2010 Tentang Retribusi Perizinan Tertentu membuktikan bahwa Kabupaten Lebak berupaya melindungi kepentingan umum seperti sarana dan prasarana yang digunakan oleh masyarakat serta untuk menjaga kelestarian lingkungan daerahnya agar sesuai dengan penataan ruang yang telah diatur oleh Pemerintah Daerah yakni dengan melalui pembayaran perizinan atas kegiatan yang dilakukan oleh masyarakat.

Dalam pengurusan perizinan IMB juga kerap terjadi pungli akibat dari transparansi biaya yang kurang jelas. Banyak masyarakat yang mengeluhkan rincian biaya terkait IMB tidak disebutkan dan diberitahukan dengan jelas. Kemudian, permasalahan lain yang kerap ditemukan pada masyarakat Kabupaten Lebak adalah masyarakat belum mamahami informasi terkait pelayanan perizinan serta non perizinan yang dapat dilakukan secara online karena kurangnya sosialisasi dari dinas terkait mengenai perizinan yang dapat diakses secara online ini.

Dengan adanya latar belakang tersebut, efektivitas Izin Mendirikan Bangunan (IMB) harus dikaji lebih dalam. Karena pada realitanya, banyak masyarakat dan pengusaha yang masih kurang sadar betapa pentingnya mengantongi perizinan IMB ini serta banyak pemohon IMB yang belum merasakan kepuasan dari pelayanan yang telah diberikan.. DPMPTSP Kabupaten Lebak juga hendaknya menjadi wadah untuk beraspirasi bagi masyarakat yang membutuhkan pelayanan, sehingga pelayanan yang diberikan pegawai dapat diselenggarakan lebih maksimal.

\section{METODE PENELITIAN}

Dalam penelitian ini, metode yang digunakan oleh peneliti yaitu metode kualitatif dengan pendekatan deskriptif. Teknik pengumpulan data penelitian diambil melalui observasi, wawancara dan dokumentasi.

Metode kualitatif adalah metode penelitian yang digunakan untuk meneliti pada kondisi obyek yang alamiah, dimana peneliti adalah sebagai instrument kunci, teknik pengumpulan data dilakukan secara triangulasi (gabungan), analisis data yang bersifat induktif/kualitatif, dan hasil penelitiannya lebih menekankan makna daripada generalisasi (Sugiyono, 2018). Data kualitatif biasanya dapat berbentuk kata, kalimat, skema atau gambar.

Dalam menentukan informan, peneliti menggunakan teknik purposive sampling. Teknik purposive sampling yaitu dalam penelitiannya, pengambilan sampel dengan cara menetapkan syarat atau kriteria khusus yang selaras dengan penelitian sehingga dapat menjawab permasalahan penelitian. 
Pemilihan teknik purposive sampling dimaksudkan agar informan yang dipilih peneliti sesuai dengan kriteria yang ditetapkan serta dapat memahami permasalahan yang diteliti.

\section{HASIL DAN PEMBAHASAN}

Pelayanan publik digunakan sebagai salah satu tolak ukur keberhasilan kinerja pemerintah yang langsung dirasakan. Biasanya masyarakat dapat secara eksklusif menilai kinerja instansi pemerintah sesuai kualitas pelayanan publik yang mereka terima. Pelayanan publik dapat dirasakan langsung oleh seluruh kalangan masyarakat sehingga keberhasilan pelayanan publik dapat mengangkat citra positif instansi pemerintah dan menjadi evaluasi publik.

Masalah-masalah yang muncul dalam proses pelayanan merupakan hal yang biasa terjadi dalam pelaksanaan sebuah pelayanan. Berbagai keluhan seringkali kita dengar yaitu seperti permasalahan atau syarat yang berbelit-belit karena birokrasi yang sulit dan kaku serta sikap pegawai pemerintahan yang kurang bersahabat apalagi berkaitan dengan instansi pemerintah. Keluhan tentang kesulitan masyarakat dalam mendapatkan pelayanan yang baik dari pemerintah merupakan hal yang sudah tidak asing lagi. (Mohammad Haidar Mustaghfiri, 2017).

Menurut

Kepmenpan

(Keputusan Menteri Pendayagunaan Aparatur Negara) Nomor 63 Tahun 2004, penyelenggaraan dalam pelayanan publik harus dapat memenuhi asas-asas sebagai berikut : (1) Transparansi; (2) Akuntabilitas;
(3) Kondisional; (4) Partisipatif; (5) Kesamaan hak; (6) Keseimbangan hak dan kewajiban

\section{Efektivitas Pelayanan Pembuatan Izin Mendirikan Bangunan (IMB) Pada Dinas Penanaman Modal dan Pelayanan Terpadu Satu Pintu (DPMPTSP) Kabupaten Lebak}

Tingkat efektivitas pada DPMPTSP Kabupaten Lebak dalam melayani masyarakat sudah cukup baik karena pegawai memberikan pelayanan yang cepat dan akurat serta proses penyampaiannya yang jelas sehingga memberikan kepuasan pelayanan terhadap masyarakat. Hal tersebut dapat dilihat dari hasil penelitian berdasarkan asas pelayanan publik yakni:

\section{Transparansi}

Prosedur pelayanan yaitu tahapan-tahapan yang harus dipenuhi oleh masyarakat pada saat mengurus perizinan. Prosedur pelayanan yang diselenggarakan pemerintah seharusnya lebih mudah dipahami serta tidak berbelit-belit dan dapat diakses oleh seluruh kalangan masyarakat. (Refandy et al., 2019)

Tanggapan masyarakat mengenai kemudahan akses dalam mengajukan IMB baik secara langsung di Dinas terkait maupun melalui online, masyarakat merasa puas karena petugas pelayanan melayani mereka dengan baik dan menjelaskan prosedur secara detail.

Pada DPMPTSP Kabupaten Lebak, penyediaan informasi tentang prosedur dan biaya terkait perizinan Izin Mendirikan Bangunan (IMB) terpampang jelas pada papan informasi Standar Pelayanan Perizinan dan Non Perizinan. 
Gambar. 1.

Informasi Standar Pelayanan Perizinan dan Non Perizinan Pada Mading DPMPTSP Lebak

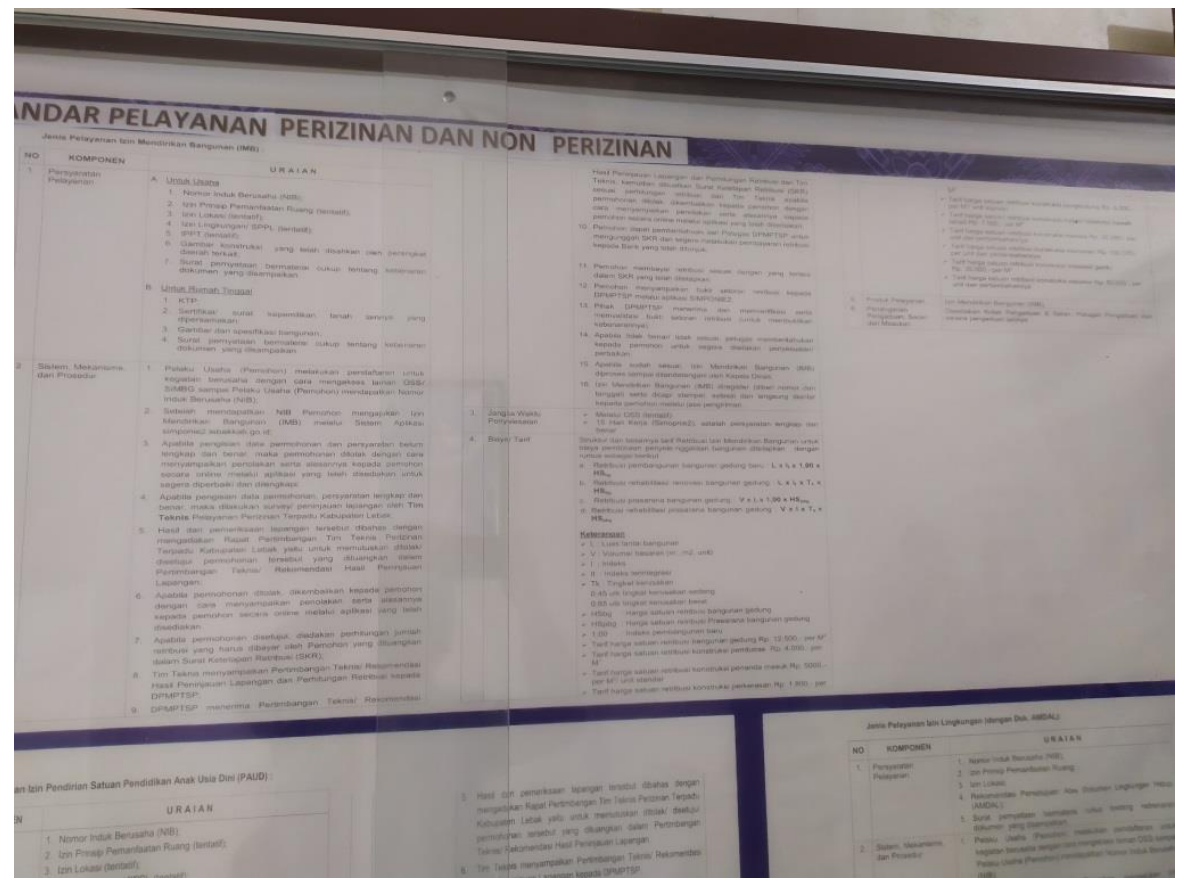

\section{Akuntabilitas}

Akuntabilitas birokrasi juga diartikan sebagai pertanggungjawaban pemerintah berupa respon pemerintah atas protes atau keluhan masyarakat mengenai penyimpangan yang terjadi pada saat proses pelayanan. (Baharuddin, 2015)

Menurut DPMPTSP Kabupaten Lebak, pelayanan yang mereka berikan sudah sesuai dengan Peraturan Bupati Lebak Nomor 65 Tahun 2017 tentang Kedudukan Susunan Organisasi Tugas dan Fungsi Serta Tata Kerja Dinas Penanaman Modal dan Pelayanan Terpadu Satu Pintu (DPMPTSP) Kabupaten Lebak.

Masyarakat juga menganggap bahwa pelayanan yang mereka terima bisa dipertanggungjawabkan dan tidak akan menimbulkan keraguan pada masyarakat karena DPMPTSP Kabupaten Lebak menjamin setiap kegiatan yang mereka laksanakan dapat dipertanggungjawabkan sesuai dengan ketentuan peraturan perundang-undangan yang secara terbuka kepada masyarakat penerima layanan.

\section{Kondisional}

Prinsip efektivitas dan efisiensi dapat tercermin melalui kegiatan pelayanan yang menyesuaikan kondisi penerima dan pemberi layanan. Mengukur tingkat efesiensi dan efektifitas dapat dilihat dari kesungguhan mereka bekerja, dan itu aplikasinya dapat langsung dirasakan oleh masyarakat. (Riyanda, 2015).

Pelayanan yang diberikan oleh pegawai DPMPTSP Kabupaten Lebak sudah sesuai dengan kondisi serta kemampuan masyarakatnya. Sehingga ketika masyarakat tidak memahami persyaratannya, pegawai dinas dengan senang membantu masyarakat. 


\section{Partisipatif}

Luasnya cakupan definisi bangunan menunjukkan bahwa hampir tidak ada kegiatan di Indonesia yang tidak membutuhkan prasarana berbentuk gedung maupun bangunan lain) baik pemerintah maupun masyarakat. Hal tersebut mengingat bahwa pada dasarnya bangunan gedung, utamanya diperuntukkan untuk kepentingan dan kebutuhan manusia. (Priyanta, 2019)

Baik DPMPTSP Kabupaten Lebak maupun masyarakat setuju bahwa partisipasi pemohon Izin Mendirikan Bangunan (IMB) semakin meningkat karena pembangunan seperti pembangunan perumahan, ruko, dan lain-lain semakin marak di Kabupaten Lebak.

\section{Kesamaan Hak}

Pelaksanaan

kebijakan

perizinan IMB sudah sepantasnya dilaksanakan secara adil. Artinya, semua kalangan di dalam masyarakat dapat menikmati hasil kebijakan secara bersama-sama. Kebijakan yang bertujuan pada aspek kesama rataan adalah kebijakan yang dapat didistribusikan kepada kelompok sasaran secara sama rata. (Mansur, 2016)

Kesamaan hak pada pelayanan yang diberikan oleh DPMPTSP Kabupaten Lebak terhadap masyarakat dibuktikan oleh penggunaan dengan sistem nomor antrian. Masyarakat juga mengakui bahwa tidak ada diskrimasi atau pembedaan terkait pelayanan yang diberikan.

\section{Keseimbangan Hak dan Kewajiban}

Aspek keseimbangan hak dan kewajiban sudah tercermin pada DPMPTSP Kabupaten Lebak yaitu pelayanan yang diberikan sudah baik dan ramah serta penyediaan kotak saran yang untuk menuangkan aspirasi masyarakat berkaitan dengan kewajiban pada saat memberikan pelayanan kepada masyarakat yang sedang melaksanakan permohonan perizinan Izin Mendirikan Bangunan (IMB).

Hambatan Pelayanan Pembuatan Izin Mendirikan Bangunan (IMB) Di Dinas Penanaman Modal Dan Pelayanan Terpadu Satu Pintu (DPMPTSP) Kabupaten Lebak

1. Pemadaman listrik

Dengan kejadian pemadaman listrik yang kerap terjadi pada saat proses pelayanan, maka server yang digunakan dalam proses pelayanan secara online menjadi terganggu. Data yang telah diinput oleh pemohon IMB kerap tidak masuk/gagal sehingga data yang telah diisi tidak terdeksi oleh petugas pelayanan yang ada di DPMPTSP Kabupaten Lebak.

\section{Kurang wawasan}

Tidak sedikit masyarakat yang belum memahami tata cara pengajuan perizinan IMB yang dilakukan secara online sehingga dapat menghambat kecepatan petugas dalam melayani proses perizinan.

Dengan diberlakukannya aturan Online Single Submission (OSS) pada proses pelayanan perizinan, maka sejumlah proses perizinan harus dilakukan secara online. Akan tetapi, DPMPTSP Kabupaten Lebak masih melayani proses perizinan secara langsung. Hanya pada saat masa pandemi ini saja proses perizinan harus dilaksanakan melalui online. 


$\begin{array}{lcr}\text { Upaya } & \text { Pemerintah } & \text { Dalam } \\ \text { Mengatasi } & \text { Hambatan } & \text { Pada } \\ \text { Pelayanan } & \text { Pembuatan } & \text { Izin } \\ \text { Mendirikan } & \text { Bangunan Di } & \text { Dinas } \\ \text { Penanaman } & \text { Modal Dan Pelayanan } \\ \text { Terpadu } & \text { Satu } & \text { (DPMPTSP) } \\ \text { Kabupaten Lebak }\end{array}$

Untuk dapat meningkatkan efektivitas pelayanan dan partisipasi masyarakat, DPMPTSP Kabupaten Lebak akan meningkatkan efektivitas pelayanan yang mereka berikan sehingga menimbulkan kepercayaan masyarakat untuk mengajukan perizinan khususnya perizinan mengenai Izin Mendirikan Bangunan (IMB) adalah sebagai berikut:

1. Meningkatkan program baru pemerintah melalui Online Single Submission (OSS)

Program baru pemerintah yang akan ditingkatkan yaitu perizinan melalui aplikasi Simponie Kabupaten Lebak yang dapat diakses pada

https://simponie2.lebakkab.go.id/.

Dengan adanya program ini, diharapkan partisipasi masyarakat dapat meningkat karena proses perizinan menjadi lebih mudah karena masyarakat tidak perlu mengantri.

Dengan meningkatnya jumlah pengajuan perizinan IMB, maka kontribusi perizinan IMB pada Pendapatan Asli Daerah (PAD) akan semakin tinggi. Hal ini seperti yang telah ditetapkan di dalam pasal 6 Undang-undang Nomor 32 Tahun 2004, sumber-sumber Pendapatan Asli Daerah (PAD) yaitu terdiri dari:

1. Pajak daerah

2. Retribusi daerah

3. Hasil pengelolaan kekayaan yang dipisahkan

4. Lain-lain pendapatan asli daerah yang sah.

2. Menggalakkan Sosialisasi IMB
Sosialisasi terkait pentingnya memiliki IMB akan lebih giat dilaksanakan oleh pemerintah agar masyarakat yang tadinya belum tahu dan masih takut untuk mengurus IMB, menjadi lebih paham dan segera mengurus perizinan IMB bangunannya.

Sosialisasi terkait perizinan Izin Mendirikan Bangunan (IMB) akan lebih difokuskan pada tata cara pengajuan perizinannya lewat online. Khususnya pada sistem berbasis web yakni

https://simponie2.lebakkab.go.id/ yang telah diluncurkan dari bulan Desember Tahun 2017 silam untuk meningkatkan efektivitas pelayanan pada DPMPTSP Kabupaten Lebak.

\section{KESIMPULAN}

Melihat dari hasil dari penelitian dan analisis yang dilaksanakan oleh peneliti tentang Efektivitas Pelayanan Izin Mendirikan Bangunan (IMB) Pada DPMPTSP Kabupaten Lebak, maka diperoleh kesimpulan sebagai berikut : (1) Tingkat efektivitas pada DPMPTSP Kabupaten Lebak pada saat melayani masyarakat sudah dikategorikan baik. Dari keenam indikator penelitian, masyarakat menunjukan respon yang baik karena pegawai memberikan pelayanan yang cepat dan akurat serta proses penyampaiannya yang jelas sehingga memberikan kepuasan terhadap masyarakat; (2) Hambatan yang dihadapi oleh DPMPTSP Kabupaten Lebak pada saat kegiatan pemberian pelayanan kepada masyarakat yakni terkait pemadaman listrik dan kurangnya wawasan masyarakat; (3) Usaha yang akan dilakukan oleh DPMPTSP Kabupaten Lebak yaitu meningkatkan program Online Single Submission (OSS) melalui

https://simponie2.lebakkab.go.id/ serta akan lebih gencar memberikan 
sosialisasi terkait pelayanan perizinan kepada masyarakat khususnya perizinan Izin Mendirikan Bangunan (IMB).

Dari kesimpulan yang telah dijelaskan di atas, saran yang diusulkan oleh peneliti antara lain : (1) Pegawai DPMPTSP Kabupaten Lebak disarankan untuk terus meningkatkan kinerja sehingga dapat lebih baik dalam memberikan pelayanan yang prima. Hal ini bertujuan supaya hubungan antara pemerintah dengan masyarakat selalu terjaga serta terjalin dengan baik; (2) DPMPTSP Kabupaten Lebak hendaknya menambah sarana juga prasarana dengan cukup seperti genset untuk menunjang program pemerintah dalam menjalankan program Online Single Submission (OSS) sebagai sistem yang dapat mengintegrasikan seluruh pelayanan perizinan dalam berusaha; (3) DPMPTSP Kabupaten Lebak hendaknya lebih gencar menjalankan sosialisasi terkait pentingnya perizinan Izin Mendirikan Bangunan (IMB) agar masyarakat maupun pelaku usaha dan investor pemohon Izin Mendirikan Bangunan (IMB) terus meningkat.

\section{REFERENSI}

Baharuddin, B. (2015). Akuntabilitas Pelayanan Publik: Studi Kasus Pelayanan Perizinan Mendirikan Bangunan di Kota Makassar. MIMBAR, Jurnal Sosial Dan Pembangunan, 31(2), 263.

Candra, G., Martius, E., \& Tanjung, F. (2018). Efektivitas Kantor Pelayanan, Perizinan, dan Penanaman Modal Kabupaten Solok dalam Pelayanan Izin Mendirikan Bangunan (IMB). Jurnal Ilmu Pemerintahan Widya Praja, 44(2), 155-166.

Irfansyah. (2015). Studi Tentang
Kontribusi Penerimaan Retribusi Izin Mendirikan Bangunan (IMB) Dalam Peningkatan Pendapatan Asli Daerah (PAD) Di Kabupaten Penajam Paser Utara. Administrasi Publik, 2(2), 1-10.

Keputusan Menteri Pendayagunaan Aparatur Negara No 63/KEP/M.PAN/7/2003. (2003). MENPAN_63_2003.pdf.

Mansur, M. (2016). Evaluasi Kebijakan Retribusi Izin Mendirikan Bangunan (Imb) Di Kabupaten Mamuju Utara. Katalogis, 4(4), 146-155.

Mohammad Haidar Mustaghfiri, P. S. (2017). Kualitas Pelayanan Penerbitan Izin Mendirikan Bangunan di Dinas Penanaman Modal dan Pelayanan Terpadu Satu Pintu Kota Surakarta. Jurnal Wacana Publik, 1(2), 24-32.

Ningsih, V., \& Hardianto, W. T. (2019). Pemondokan Pada Dinas Penanaman Modal Pelayanan Terpadu Satu Pintu ( DPMPTSP) Kota Malang. JISIP: Jurnal Ilmu Sosial Dan Ilmu Politik, 8(4), 210-216.

Priyanta, M. (2019). Regulasi Perizinan Mendirikan Bangunan dalam Mendukung Kemudahan Berusaha Menuju Bangsa yang Adil dan Makmur. Jurnal Magister Hukum Udayana (Udayana Master Law Journal), $8(3), 371$.

Refandy, R., Subarkah, S., \& Suparnyo, S. (2019). Kebijakan Peningkatan Pemungutan Ijin Mendirikan Bangunan (Imb) Sebagai Upaya Peningkatan Pendapatan Asli Daerah (Pad) Di Kabupaten Kudus. Jurnal Suara Keadilan,

Riyanda, R. (2015). Kualitas Pelayanan Pemerintahan Kota Bukittinggi Terhadap Kebijakan Perda 19/2003 Tentang IMB (Izin Mendirikan Bangunan). Cahaya Keadilan, 3(1), 32-49. 
Sampebulu, H. P. (2019). Penegakan

Hukum Pemberian Izin

Mendirikan Bangunan Di

Wilayah Bali. Mimbar Keadilan, 12(2), 238.

Steers, R. (1985). Efektivitas

Organisasi. Jakarta: Erlangga.

Sugiyono. (2018). Metode Penelitian

Kuantitatif Kualitatif dan $R \& D$.

Bandung: Alfabeta. 